\title{
O ENSINO DE CIÊNCIAS NO BRASIL: HISTÓRIA, FORMAÇÃO DE PROFESSORES E DESAFIOS ATUAIS
}

\author{
Fabrício do Nascimento ${ }^{1}$ \\ Hylio Laganá Fernandes ${ }^{2}$ \\ Viviane Melo de Mendonça ${ }^{3}$ \\ Universidade Federal de São Carlos - UFSCar \\ campus de Sorocaba
}

\section{RESUMO}

Neste artigo são discutidos aspectos históricos, epistemológicos e didáticos que orientaram o ensino de ciências no contexto brasileiro da década de 1950 até os dias atuais. São analisadas as relações existentes entre a ciência, a tecnologia e a sociedade, bem como suas influências sobre o ensino e a formação de professores de ciências. Os referenciais teóricos utilizados nas análises fundamentam-se na perspectiva sócio-histórica da educação, no entendimento da ciência como processo em permanente construção, no paradigma ciênciatecnologia-sociedade e na ideia de educação científica para todos; Entende-se o ensino de ciências e a formação docente como atividades complexas e estratégicas para o desenvolvimento do país. Preconiza-se, portanto, a urgente necessidade de oferecer aos professores uma sólida formação científica e pedagógica, bem como melhorias nas condições objetivas de trabalho que encontram no exercício da profissão. Considerando o atual contexto político, econômico e educacional brasileiro, são apontadas algumas possibilidades de mudanças no ensino de ciências a partir da implementação de uma vertente reflexiva, crítica e cidadã na formação de professores.

Palavras-chave: história do ensino de ciências; formação de professores de ciências; relação ciência-tecnologia-sociedade; paradigma CTS.

\section{THE SCIENCE TEACHING IN BRAZIL: HISTORY, TEACHER'S FORMATION AND CURRENT CHALLENGES}

\begin{abstract}
In this article we discuss the main historical, epistemological and didactic aspects that have been underlain and guided the science teaching in the Brazilian context since 1950's decade to current days. We analyze the relationships among Science, technology and society, as well as how they influence the teaching and the formation of science teachers. The theorist referential utilized in the discussion and analysis underlie in the socio-historical of education perspective, in the understanding of science as a permanent construct process, in the science-technology-society paradigm and in the idea of scientific education to all the peoples. It is understood that teaching science and teacher formation are complex and strategic activities for the country development. It is preconized, so, the urgent necessity of offering to teachers a strong scientific and pedagogical formation, as well as improvement in the objective work conditions that are found in the practicing professional. Considering the current political, economical and educational brazilian context, we point some change possibilities in science teaching from the implementation of a citizen acting in teachers' formation.

Keywords: science teaching history; science teachers formation; science-technology-society relationship; CTS paradigm.
\end{abstract}




\section{A PRODUÇÃo CIENTÍfICA E TECNOLÓGICA BRASILEIRA E SUAS RELAÇÕES COM A SOCIEDADE}

Ao longo da história, a produção científica e tecnológica brasileira foi regida ideologicamente por uma forma acadêmica e internacional de fazer ciência e sofreu com a falta de estabilidade política e o autoritarismo.

A partir dos anos 1950, as políticas científicas e tecnológicas passaram por um intenso processo de institucionalização, tendo em vista o crescimento e o progresso do país. Um aspecto marcante desse período foi a maneira mecanicista de analisar as interferências da ciência e da tecnologia sobre a sociedade, que deixava de considerar os interesses e hábitos de diferentes atores sociais em suas múltiplas relações, constituindo uma debilidade importante do pensamento dessa época (VACCAREZZA, 1999).

No final da década de 1950 e durante as décadas de 1960 e 1970, a produção científica e tecnológica brasileira esteve quase que exclusivamente sob o domínio do Estado, incluindo aquela gerada nas universidades, predominando em muitos setores uma separação formal entre pesquisa científica e produção tecnológica.

Apoiando-se em critérios de qualidade e excelência, a ciência brasileira passou a contar com legitimidade e novas formas de organização. A tecnologia manteve-se sustentada em órgãos setoriais e foi legitimada por um modelo de planificação estatal destinado à resolução de problemas práticos e à transferência de tecnologias aos setores produtivo e de defesa. Nesse período, a atividade científica focalizava principalmente os interesses da comunidade internacional e estava alheia à realidade brasileira, caracterizando-a como uma ciência endogerada, mas exodirigida (VARSAVSKY, 1979).

Mediante a aplicação de um método científico baseado na razão instrumental, na observação cuidadosa de fenômenos e na neutralidade do pesquisador esperava-se que a ciência produzisse essencialmente conhecimentos objetivos acerca das realidades natural e social. Segundo esta clássica concepção, a ciência somente poderia contribuir para o bemestar dos sujeitos se deixasse de lado as questões sociais para buscar exclusivamente as verdades científicas. As melhorias sociais somente seriam alcançadas se fosse respeitada a autonomia da ciência, ou seja, se deixasse os interesses sociais para atender exclusivamente a critérios internos de eficácia técnica. Ciência e tecnologia, portanto, eram vistas como formas autônomas da cultura e como possibilidades de compreensão e conquista da natureza (ECHEVERRÍA, 1995; GONZÁLEZ et al., 1996).

Nessa época de intenso otimismo desenvolvimentista, preconizava-se que a gestão da ciência e da tecnologia deveria ficar a cargo dos próprios cientistas e especialistas. No entanto, estas atividades não se desenvolveram de acordo com um promissor modelo ocidental linear e unidirecional, principalmente devido a uma sucessão de problemas ambientais e sociais derivados do desenvolvimento científico e tecnológico, tais como acúmulos de resíduos tóxicos, acidentes nucleares, envenenamentos farmacêuticos, derramamentos de petróleo, entre outros. A partir de então, houve a necessidade de uma revisão das políticas científicas e tecnológicas, considerando suas relações com a sociedade (MEDINA e SANMARTÍN, 1992; GONZÁLEZ et al., 1996).

Os anos 1970 foram marcados por privilegiar a ciência pura, praticamente não havendo menção às tecnologias produzidas com base em conhecimentos científicos. $\mathrm{O}$ silêncio sobre a imposição de padrões tecnológicos estrangeiros ao Brasil nesse período deveu-se à defesa de certos programas de transferência tecnológica (MACEDO, 2004).

Durante os anos 1980 e 1990, o Estado passou a diminuir suas funções reguladoras e produtivas e abriu a economia ao comércio e à competitividade internacionais. Nesse período, a globalização da economia e a homogeneização dos critérios de competitividade 
passaram a influenciar fortemente a produção científica e tecnológica brasileira, segundo princípios neoliberais. Devido à influência crescente da racionalidade utilitária e da corrente de inovação imposta pelo capital internacional, a escolha de temas e métodos de pesquisa e as oportunidades para sua realização passaram a ser definidos principalmente por grupos que detinham interesses variados, afetando não apenas a pesquisa aplicada, mas fundamentalmente a pesquisa básica. A atividade científica realizada no âmbito das universidades reencontrou seu discurso legitimador principalmente devido à importância crescente da pesquisa básica para o desenvolvimento de novas tecnologias e aos avanços nos processos de inovação industrial.

A partir dos anos 1990 tornou-se explícita a necessidade analisar a articulação existente entre ciência, tecnologia e sociedade, o que possibilitou o surgimento de um panorama muito mais complexo e de incertezas a respeito da produção científica e tecnológica, mas deixando evidente a falta de relação dessa produção com as necessidades da maioria da população brasileira.

Atualmente entende-se que a ciência se materializa em tecnologia e que esta última traz consigo a ideia de desenvolvimento do país. No entanto, o conceito de desenvolvimento que acompanhou e vem acompanhando o progresso da ciência e da tecnologia no Brasil tem sido pautado pela ideia de crescimento econômico associado a uma maior produtividade e ao aumento do consumo pelos cidadãos (MACEDO, 2004).

A ciência e a tecnologia brasileiras atuais são atividades extremamente eficazes; entretanto, é necessário questionar se seus objetivos são socialmente válidos, pois os maiores esforços em pesquisa vêm se concentrando em campos demasiadamente desvinculados dos problemas sociais cotidianos (DYSON, 1997). Muitos campos científicos e tecnológicos, além de não ajudarem a amenizar ou resolver parte significativa dos problemas sociais, estão criando mais e novos problemas, principalmente pelo fato das comissões nas quais são tomadas as decisões a respeito das políticas científicas e tecnológicas estarem geralmente constituídas por cientistas que agem essencialmente como homens de negócios (MEDINA e SANMARTÍN, 1992). Ao mesmo tempo, muitos recursos financeiros têm sido mobilizados de forma retórica para a divulgação científica com a finalidade de reforçar na sociedade uma imagem essencialista e benemérita da ciência.

Considerando os problemas sociais e ambientais causados pelo progresso científico e tecnológico, torna-se necessário abrir a ciência ao conhecimento público, desmistificar sua tradicional imagem essencialista e filantrópica, e questionar sua aplicação como atividade inevitável e benfeitora em última instância (VEIGA, 2002). Um novo contrato social faz-se necessário, tendo em vista a construção de uma ciência socialmente comprometida com as reais necessidades da maioria da população brasileira e não limitada a acumular conhecimentos e avançar sem importar em que direção. Nessa perspectiva, a ciência e a tecnologia deixariam de ser vistas como atividades autônomas que seguem apenas uma lógica interna de desenvolvimento e passariam a ser entendidas como processos e produtos nos quais aspectos não-técnicos, como valores, interesses pessoais e profissionais, pressões econômicas, entre outros, desempenham um papel decisivo em sua produção e utilização.

Torna-se necessário refletir e propor ações sobre as consequências e problemáticas de natureza social e ambiental geradas pelo desenvolvimento científico e tecnológico, principalmente no que se refere à equidade na distribuição dos custos ambientais provocados pelas inovações tecnológicas; ao uso inapropriado de determinadas descobertas científicas; às implicações éticas e à aceitação dos riscos de determinadas tecnologias; às mudanças provocadas no meio ambiente pelo exercício do poder e pela força do capital; entre outras (MEDINA e SANMARTÍN, 1992; LÓPEZ CEREZO, 1999). É nesse âmbito que reside a importância do oferecimento de uma educação científica de qualidade para 
todos os cidadãos brasileiros.

\section{AS INFLUÊNCIAS DO DESENVOLVIMENTO CIENTÍFICO E TECNOLÓGICO E DO IDEÁRIO EDUCACIONAL SOBRE O ENSINO DE CIÊNCIAS}

O desenvolvimento científico e tecnológico mundial e brasileiro exerceu e vem exercendo forte influência sobre o ensino de ciências.

A partir da Segunda Guerra Mundial, a ciência e a tecnologia transformaram-se num enorme empreendimento socioeconômico, trazendo uma maior preocupação com o estudo das ciências nos diversos níveis de ensino (KRASILCHIK, 1987; CANAVARRO, 1999).

A partir dos anos 1950, as propostas educativas do ensino de ciências procuraram possibilitar aos estudantes o acesso às verdades científicas e o desenvolvimento de uma maneira científica de pensar e agir (FROTA-PESSOA et al, 1987).

Até o início dos anos 1960 havia no Brasil um programa oficial para o ensino de ciências, estabelecido pelo Ministério da Educação e Cultura (MEC). Em 1961, a Lei de Diretrizes e Bases da Educação Nacional (LDBEN $n^{\circ}$ 4024/61) descentralizou as decisões curriculares que estavam sob a responsabilidade do MEC. Nesse período, a mais significativa busca por melhorias no ensino de ciências em âmbito nacional foi a iniciativa de um grupo de docentes da Universidade de São Paulo, sediados no Instituto Brasileiro de Educação, Ciência e Cultura (IBECC), que se dedicou à elaboração de materiais didáticos e experimentais para professores e cidadãos interessados em assuntos científicos.

Um aspecto marcante da década de 1960 foi a chegada ao Brasil das teorias cognitivistas, que consideravam o conhecimento como sendo um produto da interação do homem com seu mundo e enfatizavam os processos mentais dos estudantes durante a aprendizagem. No entanto, somente no início dos anos 1980 é que essas teorias passaram a influenciar significativamente o ensino de ciências. As teorias de Bruner e o construtivismo interacionista de Piaget valorizavam a aprendizagem pela descoberta; o desenvolvimento de habilidades cognitivas; sugeriam que os estudantes deveriam lidar diretamente com materiais e realizar experiências para aprender de modo significativo e que o professor não deveria ser um transmissor de informações, mas orientador do ensino e da aprendizagem.

O golpe militar de 1964 possibilitou o surgimento de um modelo econômico que gerou uma maior demanda social pela educação. A crise do sistema educacional brasileiro foi agravada pelo fato da expansão da rede de ensino não ter sido acompanhada de investimentos em educação na mesma proporção por parte do governo. Essa crise serviu de justificativa para a assinatura de diversos convênios entre determinados órgãos governamentais brasileiros e a United States Agency for International Development (USAID), alguns destes permanecendo vigentes até 1971. A USAID preconizava que o governo brasileiro atuasse sobre escolas, conteúdos e métodos de ensino, no sentido de oferecer aos estudantes uma formação científica mais eficaz, tendo em vista o desenvolvimento do país segundo os interesses do governo estadunidense.

A partir de 1964, as propostas educativas para o ensino de ciências sofreram grande influência de projetos de renovação curricular desenvolvidos nos Estados Unidos e na Inglaterra. Esses projetos foram liderados por renomados cientistas que estiveram preocupados com a formação dos jovens que ingressavam nas universidades, ou seja, dos futuros cientistas. Naquela época considerava-se urgente oferecer-lhes um ensino de ciências mais atualizado e mais eficiente (KRASILCHIK, 1998). O IBECC adaptou alguns desses projetos para as escolas brasileiras, entretanto, o pequeno impacto de suas propostas educativas deveu-se principalmente à resistência dos professores, que não receberam treinamento adequado, e ao descuido com algumas traduções. Um dos manuais, por 
exemplo, sugeria que os estudantes levassem "um pouco de neve" para a sala de aula para a realização de determinadas atividades experimentais (CHASSOT, 2004).

A partir da crescente industrialização brasileira e de um relativo desenvolvimento científico e tecnológico, a partir de meados dos anos 1960 importantes temas relacionados às descobertas científicas passaram a fazer parte do ensino de ciências. Esse ensino passou a ter como objetivos essenciais levar os estudantes à aquisição de conhecimentos científicos atualizados e representativos do desenvolvimento científico e tecnológico e vivenciar os processos de investigação científica. As equipes técnico-pedagógicas, ligadas às secretarias de educação e as instituições responsáveis pela formação de docentes passaram a atualizar os conteúdos para o ensino de ciências, a elaborar subsídios didáticos e a oferecer cursos de capacitação aos professores.

Nesse período, as mudanças curriculares preconizavam a substituição de métodos expositivos de ensino por métodos ativos e enfatizavam a importância da utilização do laboratório no oferecimento de uma formação científica de qualidade aos estudantes. As atividades educativas tinham por finalidade motivá-los e auxiliá-los na compreensão de fatos e conceitos científicos, facilitando-lhes a apropriação dos produtos da ciência. Fundamentadas no pressuposto do aprender-fazendo, tais atividades deveriam ser desenvolvidas segundo uma racionalidade derivada da atividade científica e tinham a finalidade de contribuir com a formação de futuros cientistas (KRASILCHIK, 1987).

Em 1965, o MEC criou Centros de Ciências nos Estados da Bahia, Minas Gerais, Pernambuco, Rio de Janeiro, Rio Grande do Sul e São Paulo, tendo em vista divulgar a ciência na sociedade e contribuir com a melhoria do ensino de ciências que vinha sendo oferecido nas escolas.

Criada em 1967, a Fundação Brasileira para o Desenvolvimento do Ensino de Ciências (FUNBEC), sediada na Universidade de São Paulo, produzia guias didáticos e de laboratório, kits para a realização de experimentos com o uso de materiais de baixo custo e oferecia atividades de treinamento aos professores. Desenvolvidas paralelamente às propostas oficiais do MEC, as atividades educativas promovidas por esta instituição procuravam levar os estudantes a descobrirem como funcionava a ciência e a desenvolverem o pensamento científico.

Apesar dos esforços para que ocorressem mudanças, durante a década de 1960 o ensino de ciências continuou focalizando essencialmente os produtos da atividade científica, possibilitando aos estudantes a aquisição de uma visão neutra e objetiva da ciência.

$\mathrm{Na}$ década de 1970, o projeto nacional do governo militar preconizava modernizar e desenvolver o país num curto período de tempo. O ensino de ciências era considerado um importante componente na preparação de trabalhadores qualificados, conforme estabelecido na Lei de Diretrizes e Bases da Educação Nacional (LDBEN n ${ }^{\circ}$ 5692/71). No entanto, ao mesmo tempo em que a legislação valorizava as disciplinas científicas, na prática elas foram bastante prejudicadas pela criação de disciplinas que pretendiam possibilitar aos estudantes o ingresso no mundo do trabalho. Prejudicou-se a formação básica sem que houvesse benefício para a profissionalização (KRASILCHIK, 1998).

Nesse período, as propostas de melhoria do ensino de ciências estiveram fundamentadas nas teorias comportamentalistas de ensino-aprendizagem, que tiveram grande impacto na educação brasileira. O conhecimento científico assumia um caráter universalista, pois, em seu processo de hegemonizar-se como a única referência para a explicação do real, a ciência procurava levar os sujeitos a substituir crenças religiosas, determinadas práticas cotidianas e as ideias de senso comum por uma nova crença, a crença na objetividade (MACEDO, 2004).

Ao longo dos anos 1970, o ensino de ciências esteve fortemente influenciado por 
uma concepção empirista de ciência, segundo a qual as teorias são originadas a partir da experimentação, de observações seguras e da objetividade e neutralidade dos cientistas. Preconizava-se que os estudantes vivenciassem o método científico. $\mathrm{O}$ estabelecimento de vínculos entre os procedimentos de investigação científica e os processos de aprendizagem dos conhecimentos científicos pressupunha a realização de atividades didáticas que oportunizassem o estabelecimento de problemas de pesquisa, a elaboração de hipóteses, o planejamento e a realização de experimentos, a análise de variáveis e a aplicação dos resultados obtidos a situações práticas.

As atividades didáticas pressupunham a resolução de problemas através de etapas bem demarcadas, que deveriam possibilitar aos estudantes pensar e agir cientificamente. Suas finalidades educativas consistiam na valorização de sua participação ativa, no desenvolvimento de uma postura de investigação, na observação criteriosa, na descrição de fenômenos científicos e, consequentemente, na aquisição da capacidade de explicação científica do mundo. O direcionamento conferido ao ensino de ciências previa a iniciação científica em um primeiro momento, a compreensão da ciência como extensão e a educação científica como um objetivo terminal (HENNIG, 1994).

$\mathrm{Na}$ perspectiva da redescoberta científica, as aulas práticas eram entendidas como o principal meio para garantir a transformação do ensino de ciências, visto que estas possibilitariam aos estudantes a realização de pesquisas e a compreensão do mundo científico-tecnológico em que viviam. Apesar de serem desenvolvidos a partir de uma seqüência de passos rígidos e mecânicos, os experimentos deveriam garantir aos estudantes o desenvolvimento de habilidades como a capacidade de tomar decisões, de resolver problemas e de pensar lógica, racional e cientificamente (FROTA PESSOA et al., 1987). Considerava-se que, vivenciando e memorizando os diferentes passos de uma pesquisa científica, os estudantes seriam capazes de realizar suas próprias investigações.

Ainda que o método científico fosse um pressuposto educativo amplamente aceito no cenário educacional, foram grandes as dificuldades de formação e treinamento de professores, principalmente no sentido de levá-los a implementar determinadas propostas educativas, mesmo considerando a elaboração de subsídios importantes como a didática de ciências através de módulos instrucionais, fundamentada nas teorias comportamentalistas de ensino-aprendizagem (JOULLIÉ e MAFRA, 1980).

O final dos anos 1970 foi marcado por uma severa crise econômica e por diversos movimentos populares que passaram a exigir a redemocratização do país. Nesse período, houve grande preocupação em relação ao ensino e à aprendizagem dos conteúdos científicos, bem como ao desenvolvimento de habilidades científicas pelos estudantes, visto que o país necessitava enfrentar a "guerra tecnológica" travada pelas grandes potências econômicas. Preconizava-se uma urgente reformulação do sistema educacional brasileiro, de modo a garantir que as escolas oferecessem conhecimentos básicos aos cidadãos e colaborassem com a formação de uma elite intelectual que pudesse enfrentar - com maior possibilidade de êxito - os desafios impostos pelo desenvolvimento. Nesse período, as propostas de melhoria do ensino de ciências apareciam com títulos impactantes como, por exemplo, "Educação em Ciência para a Cidadania" e "Tecnologia e Sociedade", tendo em vista contribuir com o desenvolvimento do país (KRASILCHIK, 1998). Pesquisas realizadas posteriormente demonstraram que não foram alcançados os resultados esperados, principalmente por não ter havido uma articulação entre essas propostas educativas e os processos de formação de professores.

Apesar da preocupação em possibilitar aos estudantes a compreensão dos processos de produção do conhecimento científico, o ensino de ciências continuou sendo desenvolvido de modo informativo, principalmente devido às precárias condições objetivas de trabalho 
que os professores encontravam nas escolas e às carências de formação específica que apresentavam.

No início dos anos 1980, a educação passou a ser entendida como uma prática social em íntima conexão com os sistemas político-econômicos. Desse modo, numa perspectiva crítica, o ensino de ciências poderia contribuir para a manutenção da situação vigente no país ou para a transformação da sociedade brasileira.

Em meados dos anos 1980, a redemocratização do país, a busca pela paz mundial, as lutas pela defesa do meio ambiente e pelos direitos humanos, entre outros aspectos, passaram a exigir a formação de cidadãos preparados para viver em uma sociedade que exigia cada vez mais igualdade e equidade (KRASILCHIK, 1996). Nesse período, as propostas para o ensino de ciências passaram a questionar os valores inerentes ao racionalismo subjacente à atividade científica e a reconhecer que esta não era uma atividade essencialmente objetiva e socialmente neutra. Passou-se a reconhecer que as explicações científicas apresentavam-se perpassadas por ideologias, valores e crenças, pois eram construídas a partir do pensamento e da ação dos cientistas durante os processos de investigação. A atividade científica seria, portanto, determinada ideologicamente, pois o dinamismo anterior ao próprio ato de compreensão do real mostrava-se subjacente ao produto da atividade cognoscente (CHAUÍ, 1997). Desse modo, o ensino de ciências também deveria possibilitar aos estudantes uma interpretação crítica do mundo em que viviam a partir do desenvolvimento de uma maneira científica de pensar e de agir sobre distintas situações e realidades.

Ao longo da década de 1980, as preocupações com o desinteresse dos estudantes pelas ciências, a baixa procura por profissões de base científica e a emergência de questões científicas e tecnológicas de importância social, possibilitaram mudanças curriculares no ensino de ciências, tendo em vista colaborar com a construção de uma sociedade cientificamente alfabetizada (KRASILCHIK, 1987; VEIGA, 2002). Fundamentadas pelas teorias cognitivistas, as pesquisas sobre o ensino de ciências passaram a evidenciar as aprendizagens individuais que ocorriam em situações educativas, como também as aprendizagens que ocorriam em contextos específicos e que poderiam permitir aos estudantes compreender e agir sobre as distintas realidades em que viviam. No entanto, apesar de ter sido acentuada a necessidade de possibilitar-lhes o desenvolvimento de habilidades como autonomia, participação, responsabilidade individual e social, foram enaltecidas principalmente as dimensões comportamentais e cognitivas relacionadas à aprendizagem das ciências, em detrimento da relevância social desse ensino (AIKENHEAD, 1994). Os resultados de muitas dessas pesquisas passaram a orientar a elaboração de novas propostas curriculares e a determinar novos rumos para a investigação sobre o ensino e a aprendizagem das ciências. As propostas educativas fundamentadas pelas teorias cognitivistas reiteravam a necessidade dos estudantes não serem receptores passivos de informações ou meros aprendizes, pois deveriam saber usar, questionar, confrontar e reconstruir os conhecimentos científicos.

Ainda naquela década, parte significativa das propostas educativas fundamentava-se no pressuposto da didática da resolução de problemas, tendo em vista possibilitar aos estudantes a vivência de processos de investigação científica e a formação de habilidades cognitivas e sociais. A problematização do conhecimento científico sistematizado e de situações científicas cotidianas, a realização de atividades desafiadoras para o pensamento, a utilização de jogos educativos e o uso de computadores eram vistas como possibilidades educativas que poderiam levá-los a se apropriar de conhecimentos relevantes, a compreender o mundo científico e tecnológico e a desenvolver habilidades necessárias à interpretação e possível modificação das realidades em que viviam, principalmente no 
sentido de melhoria da própria qualidade de vida (KRASILCHIK, 1987).

A partir de meados dos anos 1980 e durante a década de 1990, o ensino de ciências passou a contestar as metodologias ativas e a incorporar o discurso da formação do cidadão crítico, consciente e participativo. As propostas educativas enfatizavam a necessidade de levar os estudantes a desenvolverem o pensamento reflexivo e crítico; a questionarem as relações existentes entre a ciência, a tecnologia, a sociedade e o meio ambiente e a se apropriarem de conhecimentos relevantes científica, social e culturalmente (DELIZOICOV e ANGOTTI, 1990).

Um aspecto bastante significativo desse período foi a incorporação das ideias de Vygostsky na orientação dos processos educativos, especialmente em relação à construção do pensamento pelos sujeitos a partir de suas interações com o contexto sociocultural. Desse modo, no ensino de ciências seria importante possibilitar não apenas o contato dos estudantes com os materiais de ensino-aprendizagem, mas também com os esquemas conceituais apresentados pelo professor (KRASILCHIK, 1998). Os professores de ciências deveriam desenvolver suas ações educativas considerando a valorização do trabalho coletivo e a mediação dos sistemas simbólicos na relação entre o sujeito cognoscente e a realidade a ser conhecida, bem como planejar atividades didáticas que permitissem aos estudantes alcançar níveis mais elevados de conhecimentos e de desenvolvimento de habilidades cognitivas e sociais, oferecendo-lhes tarefas cada vez mais complexas e apoio didático para que as conseguissem realizar, inclusive com o auxílio dos colegas.

De modo a superar as estratégias de ensino baseadas essencialmente na apropriação dos produtos da ciência, as atividades educativas preconizavam possibilitar aos estudantes a construção de conhecimentos científicos segundo os pressupostos educativos da abordagem construtivista do ensino e da aprendizagem. As atividades didáticas pressupunham que, com o auxílio do professor e a partir das hipóteses e conhecimentos anteriores, os estudantes poderiam construir conhecimentos sobre os fenômenos naturais e relacioná-los com suas próprias maneiras de interpretar o mundo (CARVALHO e GIL PÉREZ, 1992).

Ao longo dos anos 90, tornaram-se mais evidentes as relações existentes entre a ciência, a tecnologia e os fatores socioeconômicos. Desse modo, o ensino de ciências deveria criar condições para que os estudantes desenvolvessem uma postura crítica em relação aos conhecimentos científicos e tecnológicos, relacionando-os aos comportamentos do homem diante da natureza (MACEDO, 2004).

Apesar de as propostas de melhoria do ensino de ciências estarem fundamentadas numa visão de ciência contextualizada sócio, política e economicamente, da segunda metade da década de 80 até o final dos anos 90 esse ensino continuou sendo desenvolvido de modo informativo e descontextualizado, favorecendo aos estudantes a aquisição de uma visão objetiva e neutra da ciência.

A partir do final dos anos 90, a educação científica passou a ser considerada uma atividade estratégica para o desenvolvimento do país, sendo esta ideia compartilhada, ao menos verbalmente, pela classe política, por cientistas e educadores, independentemente de suas visões ideológicas. Esta ideia apontava a existência de complexas interações entre a ciência e a sociedade; portanto, o simples oferecimento de uma educação científica escolar não seria suficiente para a formação de cidadãos capazes de resistir às informações pseudocientíficas que invadiam a sociedade da época. Sendo o capital humano considerado um fator essencial para o desenvolvimento do país, a educação científica passou a ser vista como uma prioridade para todos, surgindo daí a necessidade de oferecimento de uma alfabetização científica aos estudantes como forma de colaboração para uma atuação crítica, consciente e cidadã (LÓPEZ CEREZO, 1999; MARCO, 1997; FOUREZ, 1997).

$\mathrm{Na}$ década de 2000, as discussões a respeito da educação científica passaram a 
considerar com maior ênfase a necessidade de haver responsabilidade social e ambiental por parte de todos os cidadãos. No ensino de ciências, portanto, as questões relacionadas à formação cidadã deveriam ser centrais, possibilitando aos estudantes reconsiderar suas visões de mundo; questionar sua confiança nas instituições e no poder exercido por pessoas ou grupos; avaliar seu modo de vida pessoal e coletivo e analisar previamente a consequência de suas decisões e ações no âmbito da coletividade.

Atualmente, o movimento educação científico-tecnológica para todos (FOUREZ, 1997) e a ideia de alfabetização científica para todos (MARCO, 1997) pressupõem a formação de cidadãos capazes de fazer opções de modo consciente, bem como a existência de amplas relações entre a ciência, a tecnologia, a sociedade e o meio ambiente (JIMÉNEZ e OTERO, 1990; GIL PÉREZ, 1991; MEMBIELA, 1995; FOUREZ, 1997; YUS, 1997; HODSON e REID, 1998; GIL PÉREZ, 1999; VEIGA, 2002).

São muitas as razões apontadas por esses autores para a revisão do papel da educação científica no contexto atual, sendo a principal aquela que defende a incorporação nos currículos escolares de temas relacionados às transformações sociais e ambientais geradas pelo desenvolvimento científico e tecnológico, pois consideram que isso poderia revolucionar profunda e positivamente o ensino de ciências, contribuindo para incrementar sua utilidade e o interesse dos estudantes (GIL PÉREZ, 1999). Tal proposta assemelha-se ao movimento que levou cientistas e educadores a insistirem na introdução da educação científica na cultura geral no final dos anos 70 e à excessiva importância conferida ao ensino de ciências na década de 1990 com relação à formação cidadã e ao desenvolvimento social (FOUREZ, 1997). A mera abordagem de temas polêmicos e de questões científicas e tecnológicas atuais, que têm implicações na vida dos cidadãos e nos rumos da humanidade, poderia conduzir a resultados tão decepcionantes como os que foram alcançados com a busca por melhorias da educação científica do país nos anos 1960 e 1970 (GIL PÉREZ, 1999). É necessário que os estudantes percebam a mutabilidade do conhecimento científico e se atualizem permanentemente num mundo marcado por uma intensa produção científica e tecnológica e que passa por constantes e profundas mudanças.

Atualmente, muitos são os argumentos científicos, sociais, éticos e educacionais estabelecidos pela ideia de compreensão pública da ciência (WYNNE, 1995; GONÇALVES, 2000; VEIGA, 2002), o que pressupõe o ingresso da ciência na cultura, no sentido de que o saber científico seja partilhado por todos os cidadãos:

[...] o conhecimento científico, saído do seu contexto de produção, entra na esfera pública, ou seja, num outro contexto impregnado de fatores culturais, sociais, econômicos e políticos, fatores que levam à reinterpretação e renegociação desse conhecimento em função de seu contexto de produção e utilização. (VEIGA, 2002, p. 54)

No entanto, ainda é marcante o distanciamento entre os pressupostos educativos do ensino de ciências e as possibilidades de torná-los concretos, o que se deve a uma complexa relação epistemológica entre as ideias científicas e os pressupostos da educação científica (HODSON, 1986; NASCIMENTO, 2009); às dificuldades dos professores em romper com uma profunda concepção positivista de ciência e com uma concepção conservadora e autoritária de ensino-aprendizagem como acumulação de informações e de produtos da ciência, que seguem influenciando e orientando suas práticas educativas; às suas carências de formação geral, científica e pedagógica; às inadequadas condições objetivas de trabalho que encontram no exercício da profissão e a determinadas políticas educacionais fundamentadas em princípios contraditórios à formação crítica dos cidadãos. 


\section{A FORMAÇÃO DE PROFESSORES DE CIÊNCIAS NO BRASIL}

Nos últimos trinta anos no Brasil, a formação de professores tornou-se objeto de pesquisa acadêmica e se constituiu como um importante foco das políticas educacionais.

Ao contrário do que ocorreu nas décadas de 1950 e 1960, período no qual a educação brasileira esteve fortemente influenciada pelos pressupostos educativos da psicologia comportamental, a produção de conhecimentos sobre a formação e a atuação de professores vem superando uma visão meramente técnica a respeito da atividade docente.

Nos cursos de formação de professores de ciências, a tendência tecnicista predominante de meados dos anos 1960 até o início dos anos 1980 reforçou problemas já existentes como o tratamento neutro, universal e estritamente científico dos componentes curriculares; a dicotomia teoria/prática; a fragmentação das disciplinas de formação geral e o distanciamento entre as realidades escolar e social. O papel do professor de ciências foi reduzido à simples execução de tarefas programadas e controladas, sendo preparado para memorizar as informações científicas que seriam exigidas dos estudantes e aplicar procedimentos didáticos sugeridos por especialistas em educação. A formação disciplinar, originada sob o pressuposto da disciplinaridade científica possibilitou a criação de currículos fragmentados e a especialização de saberes, de materiais didáticos e da formação docente (VIANNA, 2004).

Nesse período, as teorias comportamentalistas de ensino-aprendizagem influenciaram significativamente a formação de professores. O professor era visto como um técnico capaz de estabelecer claros e precisos objetivos de ensino e planejar suas atividades educativas de forma a obter o controle da aprendizagem dos estudantes, modificando, eliminando ou introduzindo novos comportamentos nos mesmos.

A expansão da rede de ensino após o golpe militar de 1964 requereu um maior número de professores para atender a uma crescente população escolar. Quanto ao ensino de ciências, essa demanda foi suprida principalmente pela expansão do ensino universitário privado com a criação indiscriminada de cursos de licenciatura de curta duração em faculdades isoladas e pela permissão do exercício profissional de docentes não-habilitados, contribuindo para descaracterizar e desvalorizar ainda mais a profissão docente.

Em 1968, a Lei $\mathrm{n}^{\circ}$ 5.540/68 reestruturou o ensino universitário, criou a estrutura departamental e possibilitou a criação dos institutos, que passaram a responsabilizar-se pela formação de professores de ciências, ficando a formação pedagógica sob a responsabilidade das faculdades de educação. Os cursos de formação, que já eram extensos e descritivos, com aulas de laboratório que visavam apenas confirmar a teoria já ensinada, se tornaram ainda mais conteudistas (CHASSOT, 2004).

Na década de 60, com a chegada das teorias cognitivistas ao Brasil, principalmente do construtivismo interacionista de Piaget, a imagem do professor como um transmissor de informações foi substituída pela imagem do orientador de experiências educativas e de aprendizagens (MARTINS, 2004). Tal ideia passou a fomentar as discussões a respeito da necessidade de mudanças nas propostas de formação de professores. Nessa perspectiva, os professores de ciências deveriam desenvolver suas ações educativas respeitando as singularidades e as fases de desenvolvimento intelectual dos estudantes, estimulando-os num processo de superação constante de obstáculos cognitivos e didáticos.

A formação de professores passou a ser discutida nas principais conferências sobre educação principalmente a partir do final dos anos 1970 e início dos 1980, quando esteve em discussão a necessidade de reformulação dos cursos de licenciatura.

$\mathrm{Na}$ primeira metade da década de 1970, ainda sob influência das teorias comportamentalistas de ensino-aprendizagem e da tecnologia educacional, a formação de 
professores de ciências privilegiava a dimensão técnica e a instrumentalização de sua ação educativa. Predominava uma visão funcionalista da educação, onde a experimentação, a racionalização, a exatidão e o planejamento tornaram-se as principais questões na formação desses profissionais (PEREIRA, 2006).

A partir de meados dos anos 1970, especialistas e pesquisadores em educação passaram a criticar a formação oferecida aos professores, dando origem a um movimento de oposição e rejeição aos enfoques técnico e funcionalista. A incorporação da dialética marxista na análise da educação escolar possibilitou destacar o papel crítico e revolucionário que deveria ser assumido pelos professores. Nos processos educativos cabia a estes profissionais discutir com os estudantes as contradições existentes na sociedade brasileira, deixando evidentes as relações entre opressores e oprimidos através de um trabalho de conscientização e politização, tendo em vista a luta pela reversão da escola excludente brasileira (VIANNA, 2004). No entanto, a adoção de ideias e práticas educativas que visavam a formação crítica e político-social dos estudantes não foi tolerada pelo regime autoritário vigente no país.

Entre o final dos anos 1970 e início dos anos 1980, o ideário pedagógico mundial atingiu um significativo nível de qualidade e multiplicidade, principalmente com o surgimento da teoria crítica, das teorias crítico-reprodutivistas, das teorias antiautoritárias, entre outras. As teorias educacionais que consideravam a escola como reprodutora das relações sociais permearam as discussões sobre a atuação de professores e influenciaram algumas disciplinas dos cursos de formação. Devido às limitações dessas teorias e à compreensão da educação a partir de seus condicionantes históricos e político-sociais, esta passou a ser considerada uma atividade plural e complexa. Nessa perspectiva, a escola era vista como um espaço de contradições, no qual novas ideias e mudanças poderiam ser gestadas e implementadas (PEREIRA, 2006).

No início da década de 1980, a tecnologia educacional passou a ser questionada pela crítica marxista, contrária ao oferecimento aos docentes de uma formação desvinculada dos aspectos político-sociais. Considerava-se que o idealismo inerente à visão abstrata da cultura e o positivismo que fundamentava a visão tecnicista não seriam suficientes para garantir uma formação docente de qualidade. No entanto, as teorias críticas não ressoaram de modo significativo nos cursos de formação de professores de ciências, pois estes continuaram sendo desenvolvidos segundo os enfoques técnico e funcionalista.

Nos primeiros anos da década de 1980, com o surgimento de novas teorias relacionadas aos processos educativos, a docência passou a ser vista como uma atividade complexa. As discussões a respeito da formação do professor de ciências privilegiaram o caráter político da prática pedagógica e seu compromisso com os interesses das classes populares, o que se articulava ao movimento da sociedade brasileira na busca de superação do autoritarismo vigente desde o golpe de 1964 e da redemocratização do país. Nesse período, as políticas educacionais orientavam a formação docente no sentido de garantir a qualidade do ensino a ser desenvolvido nas escolas, porém, desconsideravam os aspectos desqualificadores aos quais os professores estavam submetidos. Procurava-se formar um profissional que seria "de-formado" no próprio trabalho (ARROYO, 1985).

Em 1980, o Comitê Nacional Pró-Formação do Educador iniciou um movimento pela reformulação dos cursos de formação de professores no Brasil e sugeriu a extinção dos cursos de licenciatura de curta duração. Em 1983, o MEC criou a Comissão Nacional de Reformulação dos Cursos de Formação do Educador (CONARCFE), deixando evidente uma lacuna entre as intenções governamentais e as posições defendidas por especialistas e pesquisadores em educação. Os problemas relacionados às licenciaturas curtas e plenas transformaram-se em pautas das diversas instâncias de discussão do Movimento Nacional 
de Reformulação dos Cursos de Formação de Educadores.

$\mathrm{Na}$ primeira metade da década de 1980, os debates sobre a formação docente sugeriam que o professor deveria conscientizar-se a respeito da função da escola na transformação da realidade social dos estudantes e das articulações da prática educativa com a prática social mais ampla. Os cursos de licenciatura em ciências deveriam, portanto, formar educadores, ressaltando assim a primazia do ato de educar sobre o ato de ensinar. A imagem do educador dos anos 1980 apareceu em oposição à figura do especialista de conteúdo, ao facilitador de aprendizagem, ao organizador das condições de ensinoaprendizagem, ao técnico da educação dos anos 1970. Nos anos 1990, entretanto, a dicotomia professor/educador passou a ser considerada uma questão de menor importância no contexto educacional brasileiro (PEREIRA, 2006). Preconizava-se que, para atuar de maneira eficaz e consequente com as necessidades formativas dos estudantes, o professor deveria ter competência técnica e qualidade formal e política, aspectos que pressupunham mudanças significativas nos cursos de formação inicial.

Por não considerarem o processo de formação docente em seus aspectos sóciopolítico-econômicos, parte significativa das investigações realizadas até meados dos anos 1980 apresentava críticas genéricas à formação e à atuação do professor, pouco contribuindo para a compreensão de seus aspectos determinantes e para a busca de superação dos problemas detectados. Outros estudos, porém, apontaram a precariedade dos processos de formação de professores e problemas relacionados aos currículos dos cursos, aos temas e conteúdos desenvolvidos nas disciplinas de formação geral e específica, às estratégias de ensino utilizadas pelos professores formadores, à falta de delineamento de um perfil desejável para essa formação, entre outros aspectos.

Em meados dos anos 1980, as discussões sobre a formação de professores passaram a incorporar a relação teoria-prática, sendo esta uma questão recorrente até o momento. A formação docente passou a ser vista segundo uma perspectiva multidimensional, na qual deveriam estar integradas as dimensões humana, técnica e político-social. Surgiram severas críticas aos currículos dos cursos de formação docente, pois estes continuavam apoiados na ideia de acúmulo de conhecimentos teóricos para posterior aplicação no âmbito da prática, sendo esta visão coerente com a lógica da racionalidade técnica, segundo a qual a atividade profissional consistiria na resolução de problemas instrumentais por intermédio da aplicação da teoria e da técnica científicas (SCHÖN, 1992).

Por ser a principal instituição responsável pela formação de professores, a universidade passou a ser criticada não apenas pela formação que oferecia, mas principalmente por sua falta de compromisso com a reconstrução da escola pública. Devido à pluralidade de concepções inerentes às relações entre ensino, aprendizagem e desenvolvimento do país, nesse período passou-se a considerar como essencial o oferecimento de programas de educação continuada aos professores para que se mantivessem atualizados e pudessem acompanhar os avanços das ciências, das tecnologias e as complexas mudanças que caracterizavam a sociedade (VIANNA, 2004). Mudar a formação oferecida aos professores tornou-se uma prioridade para a melhoria do ensino de ciências, o que favoreceu o surgimento de diversas propostas elaboradas por especialistas ligados às universidades públicas do país, tais como cursos de aperfeiçoamento didático, programas de formação continuada, projetos de educação científica, entre outros. No entanto, foi pouco significativo o reflexo dessas propostas sobre a atuação dos professores e sobre o ensino de ciências (NASCIMENTO, 2009).

Entre o final dos anos 1980 e início dos 1990, as mudanças ocorridas no cenário internacional repercutiram intensamente no pensamento educacional brasileiro, deixando evidente a necessidade de incorporar as visões micro e macro-sociais nos processos de 
formação docente e de possibilitar a formação do professor reflexivo e pesquisador de sua própria prática educativa. Nesse período, a interação entre a universidade e a escola de $1^{\circ} \mathrm{e}$ $2^{\circ}$ graus passou a fazer parte dos debates educacionais, o que possibilitou o surgimento de diversas propostas de treinamento em serviço ou reciclagem através do oferecimento de cursos aos professores das escolas públicas. Tais propostas foram bastante criticadas no meio acadêmico e consideradas insuficientes devido a seu caráter esporádico e à falta de vínculo com a realidade e as necessidades dos professores. A partir de então, as pesquisas passaram a focalizar a relação existente entre as condições de formação e de atuação dos professores, apontando a necessidade de mudanças nos cursos de formação, de melhoria das condições objetivas de trabalho nas escolas e de estímulo à formação continuada.

Em meados dos anos 1990, com a promulgação da nova Lei de Diretrizes e Bases da Educação Nacional (LDBEN n 9394/96) e a elaboração dos Parâmetros Curriculares Nacionais (PCNs) para o Ensino Fundamental e o Ensino Médio, as escolas deveriam possibilitar aos estudantes uma formação geral de qualidade, tendo em vista levá-los ao desenvolvimento de capacidades de pesquisar, buscar informações, analisá-las e selecionálas, assim como da capacidade de aprender a aprender, ao invés do simples exercício de memorização. Essa formação, portanto, deveria ter como foco a aquisição de conhecimentos básicos, a preparação científica e a capacidade de utilizar diferentes tecnologias.

Nesse sentido, equipes ligadas ao Ministério da Educação e especialistas em educação de diversas universidades passaram a elaborar e desenvolver propostas de formação continuada de professores que procuravam romper com uma educação descontextualizada e compartimentalizada, que valorizava essencialmente o acúmulo de informações pelos estudantes. Procurava-se levar os professores de ciências a ensinarem os conteúdos escolares para além da dimensão conceitual, de modo a possibilitar aos estudantes não apenas a formação de habilidades cognitivas, mas também sociais. Preconizava-se que o êxito dessa formação somente seria alcançado se os futuros professores tivessem oportunidades de vivenciar situações reais de ensino-aprendizagem, de refletir criticamente sobre as mesmas, de pesquisar e atuar criticamente a partir de um projeto pedagógico próprio e de se apropriar efetivamente de conhecimentos científicos e pedagógicos relevantes, o que não se efetivou na maioria dos cursos de formação de professores de ciências, pois estes continuaram sendo desenvolvidos segundo a lógica da racionalidade técnica.

Ao longo da década de 1990 foram realizadas significativas investigações sobre os processos de formação prática do professor, que ocorriam no exercício da docência. Considerando que no cotidiano de sua atividade o professor construía gradativamente conhecimentos sobre sua profissão, as análises sobre os saberes docentes possibilitaram vislumbrar uma perspectiva que passou a considerar os professores como profissionais produtores de saber e de saber-fazer (NÓVOA, 1992). Além desse pressuposto, nesse período, as propostas de formação de professores de ciências também passaram a incorporar, ao menos em seus projetos pedagógicos, as relações existentes entre a ciência, a tecnologia e a sociedade. Esperava-se superar a transmissão de fatos e conceitos científicos e o oferecimento de técnicas didáticas e possibilitar aos futuros professores condições de compreenderem criticamente os aspectos que orientavam suas práticas educativas e as ideologias que regiam a sociedade e a educação. Acreditava-se que, refletindo criticamente sobre seu papel e sobre as possibilidades educativas do ensino de ciências, o professor poderia levar os estudantes a passarem do nível da aparência para o nível da interpretação científica e a construírem saberes estratégicos essenciais para a transformação da sociedade. A concretização de tais pressupostos educativos não seria conseguida pela simples rejeição ao ensino tradicional, pois sua transformação exigiria dos professores conhecimentos 
profundos a respeito de suas deficiências e a elaboração de um modelo educativo igualmente coerente e eficaz (GIL PÉREZ, 1991).

Do início da década de 1990 até o ano de 2001 as políticas do governo federal estiveram fundamentadas num discurso moralizante e na ideia de eficiência segundo preceitos neoliberais. Nesse período, a formação docente esteve subordinada às propostas educativas elaboradas por equipes técnicas ligadas ao Ministério da Educação e a determinadas universidades, ficando a participação dos professores restrita à execução dessas propostas, deixando evidente uma tendência de atribuir a responsabilidade pela formação e pela melhoria do ensino aos próprios professores, como se estas fossem tarefas meramente individuais associadas a esforço e mérito pessoais.

A influência neoliberal levou algumas instituições formadoras a direcionarem a formação continuada de docentes para o atendimento às demandas de determinados setores da indústria e do comércio, como, por exemplo, os setores editorial e de informática educacional, tendo em vista tornar os profissionais da educação e os estudantes, clientes das escolas, em vorazes consumidores de subsídios didáticos. Segundo esta visão, a orientação da formação não recaía sobre as necessidades de docentes e estudantes, mas sobre os interesses desses setores. Os professores deveriam passar por treinamentos, dominar técnicas didáticas e participar de maneira alienada de um processo que procurava fazer da escola o principal meio de transmissão da visão neoliberal e um mercado para os produtos da indústria cultural e da informática (GENTILI e SILVA, 1999).

Nessa época, as políticas educacionais do governo brasileiro estiveram atreladas às diretrizes do Banco Mundial, que limitavam a formação dos professores a um papel ainda mais alienado, haja vista que eram insumos caros. Procurou-se transformar os professores em operadores de ensino, depositando-se grandes esperanças nos livros didáticos, nas modernas tecnologias de educação à distância e nas propostas de auto-aprendizagem, vistas como mais custo-efetivas e rápidas do que o investimento em formação docente, segundo uma tendência não apenas de desprofissionalização, mas de exclusão dos próprios professores como sujeitos e profissionais (TORRES, 1998). A orientação política desse período permitiu que as condições concretas para o exercício profissional da docência não fossem alteradas, sendo empregados artifícios considerados mais custo-efetivos para os governos, embora o discurso usado para vender pacotes didáticos como compensadores das péssimas condições objetivas de trabalho e de formação dos docentes camuflasse tais justificativas (MIZUKAMI et al., 2002).

Diante da constatação dos inúmeros problemas inerentes à formação inicial de professores, em meados dos anos 90, a LDBEN n 9394/96 estabeleceu mudanças nessa formação. No entanto, as políticas governamentais a desqualificaram ainda mais, sendo oferecidos programas de treinamento em serviço, sem a garantia de que esta modalidade de formação possibilitaria melhorias na educação básica. A formação em serviço tratava-se de mera atualização da formação recebida segundo um pressuposto que enfatizava a necessidade de reciclagem desses profissionais (CANDAU, 1996).

Contrariamente à visão neoliberal, ao longo dos anos 90 foram desenvolvidos diversos estudos que possibilitaram construir uma nova concepção de formação continuada, enfatizando a escola como um espaço privilegiado para a realização desta formação e considerando os processos de formação a partir do reconhecimento e da valorização dos saberes docentes, assim como as diferentes etapas do desenvolvimento profissional dos professores. Subjacente à maior parte das pesquisas e atividades relacionadas à formação de professores, realizadas nesse período, prevaleceu uma concepção crítica de educação, passando as atividades formativas a considerar a necessidade de compreender as práticas educativas realizadas em diferentes contextos e de valorizar a capacidade de produção de 
conhecimentos por parte dos professores, sendo a reflexão a principal base para a aprendizagem e para o desenvolvimento profissional da docência (ZEICHNER, 1993).

Nesse período, as propostas de formação de professores de ciências passaram a considerar com maior ênfase a importância da reflexão sobre as práticas concretas desenvolvidas nas escolas e sobre as articulações existentes entre a educação e o contexto sócio-político-econômico. Tornou-se ainda mais explícita a necessidade do professor vir a ter compromisso com a educação e com a sociedade, pois, sendo capaz de refletir e posicionar-se a respeito de problemas concretos, este profissional poderia vir a se tornar um agente de mudanças em seu contexto de atuação. Apesar dos processos econômicos, políticos e sociais condicionarem a atuação dos professores, considerava-se que no âmbito da sala de aula prevaleceria sua autonomia, aspecto próprio e particular do trabalho docente, pois o controle por parte do Estado se efetivaria em suas práticas educativas principalmente pela formação pouco consequente que apresentavam, ou seja, pela carência de conhecimentos científicos e pedagógicos e pela falta de visão crítica a respeito da função social do trabalho que desenvolviam (BASSO, 1994).

A formação docente também passou a ser vista sob a perspectiva da investigaçãoação (SCHÖN, 1992) e a atuação do professor a ser considerada uma atividade complexa que requeria as habilidades de saber, de fazer e de saber-fazer. Para desenvolver um ensino consistente e consequente com as necessidades formativas dos estudantes, o professor de ciências deveria submergir-se em um processo constante de aprendizagem; apropriar-se de conhecimentos relevantes científica, cultural e socialmente e posicionar-se criticamente para poder responder efetivamente às demandas do contexto de atuação. Considerando as rápidas transformações de natureza política, social, científica e tecnológica do país e do mundo, esse profissional deveria manter-se em atitude de atualização constante, principalmente porque não se encontraria completamente formado e preparado para atuar apenas com os conhecimentos adquiridos durante sua formação inicial. Assim como outros profissionais, deveria aprender e aperfeiçoar sua prática educativa continuamente.

Atualmente, a formação de professores vem sendo considerada uma atividade estratégica no âmbito das políticas educacionais, principalmente devido ao importante papel que esses profissionais podem representar nas transformações educativas e sociais (GIMENO SACRISTÁN, 1983; PÉREZ GÓMEZ, 1992; DEMO, 2002). Nesse sentido, o oferecimento de uma sólida formação científica e pedagógica aos professores vem se configurando progressivamente como imprescindível para o desenvolvimento dos sistemas educativos, sendo feitos cada vez mais esforços na tentativa de melhoria dos processos de formação inicial e continuada de professores no Brasil. Parece haver um consenso entre os especialistas em educação quanto à ideia de que a formação inicial é insuficiente para garantir o desenvolvimento profissional (CANDAU, 1996; MIZUKAMI, 1996). Defendese, portanto, uma formação de caráter permanente que valorize as práticas educativas realizadas pelos professores no dia-a-dia da escola e o conhecimento que provém das pesquisas realizadas na universidade, de modo a articular teoria e prática na formação e na construção do conhecimento profissional do professor.

O Plano Nacional de Educação (PNE), aprovado pela Lei no 10.172, de 09/01/2001, está em consonância com a Constituição Federal e com a LDBEN n ${ }^{\circ} 9394 / 96$, sendo um de seus objetivos a valorização dos profissionais da educação. No entanto, ainda que nos últimos anos tenham sido produzidos significativos conhecimentos a respeito de práticas formativas e educativas realizadas em distintos contextos, ainda são evidentes as dificuldades de implementação de mudanças nas propostas de formação de professores de ciências, principalmente pelo fato de muitos cursos de formação continuarem apresentando um caráter estritamente disciplinar e essencialmente cognitivo. 


\section{PERSPECTIVAS PARA O ENSINO DE CIÊNCIAS NO CONTEXTO ATUAL A incorporação do paradigma ciência-tecnologia-sociedade no ensino de ciências}

Até o final dos anos 1970, o pensamento a respeito da produção científica e tecnológica brasileira foi construído essencialmente como um discurso teórico-ideológico, originado na práxis científica e política de seus idealizadores. Tal pensamento apresentava pouca reflexão teórica e conceitos próximos às suas experiências imediatas e pessoais (VACCAREZZA, 1999). A partir dos anos 1980, diversos estudos passaram a indicar as possíveis contribuições da ciência na construção de uma sociedade verdadeiramente democrática e integradora, que pudesse superar as novas expressões do elitismo e da fragmentação social. A crítica sobre a dependência cultural pretendeu revolucionar a produção científica e tecnológica e a percepção de suas relações com a sociedade, contrariamente ao esforço intelectual dos anos 1960 e 1970, que se desenvolveu rumo a um conformismo quanto ao papel social dessas atividades.

A complexidade dos problemas científicos e tecnológicos atuais passou a exigir uma maior flexibilidade interpretativa a partir de distintos referenciais teóricos. $\mathrm{O}$ questionamento dos ideais de cientificidade, que impõem à ciência critérios e finalidades de caráter objetivo, neutro e descontextualizado, passou a fazer parte de estudos que procuravam mostrar as relações existentes entre a ciência, a tecnologia e a sociedade (estudos CTS). No final dos anos 1980, os estudos CTS apresentaram novas formas de analisar a atividade científica e tecnológica e novas possibilidades para o ensino de ciências. Apesar de apresentarem uma visão crítica a respeito da atividade científica e tecnológica, os enfoques desses estudos não constituem um campo homogêneo de análise e interpretação (IRANZO et al., 1995; ALONSO et al., 1996). Os estudos CTS passaram a enfatizar a dimensão social da ciência e da tecnologia, compartilhar certa rejeição e crítica à visão destas atividades como neutras e descontextualizadas e condenar a tecnocracia. Nesses estudos, a atividade científica e tecnológica passou a ser vista de modo contextualizado e ser entendida como um processo social (IRANZO et al., 1995; ALONSO et al., 1996).

A partir dos anos 1990, as universidades passaram a ser espaços privilegiados de produção de conhecimentos a respeito das relações existentes entre a ciência, a tecnologia e a sociedade, elevando os estudos CTS a níveis mais complexos, tanto em termos de teorização como de análise (VACCAREZZA, 1999). No campo das políticas públicas, atualmente os estudos CTS vêm defendendo a ideia de regulação pública da ciência (WYNNE, 1995; GONÇALVES, 2000; VEIGA, 2002) e a criação de espaços democráticos que poderiam promover reflexões e possivelmente a abertura dos processos de tomada de decisões em questões relacionadas às políticas científicas e tecnológicas. Segundo esta abordagem, os modelos de gestão da ciência e da tecnologia deveriam ser substituídos por modelos de regulação pública, considerando a revisão do modelo unidirecional e a elaboração de novas políticas científicas e tecnológicas. Desse modo, as relações entre ciência, tecnologia e sociedade, refletidas nas pesquisas acadêmicas, poderiam influenciar a construção de novos programas educativos e a elaboração de subsídios didáticos para o ensino de ciências numa perspectiva crítica e contextualizada (LÓPEZ CEREZO, 1999).

De modo geral, a ciência ainda é percebida pelos sujeitos como algo distante, aparentemente sem qualquer influência direta sobre sua realidade vivencial. As dificuldades de compreensão das complexas relações existentes entre as teorias científicas e técnicas, ciência pura e aplicada e teoria e prática leva-os a perceberem as ciências apenas pelos resultados de suas aplicações, favorecendo o surgimento do cientificismo, da fusão ciência/técnica e do mito da neutralidade científica. Nesse sentido, o sujeito tende a 
identificar o conhecimento científico a partir de seus efeitos tecnológicos, o que faz com que deixe de perceber que a ciência faz parte das formas econômicas e produtivas da sociedade, promovendo grandes mudanças sociais na divisão social do trabalho, produção e distribuição de bens e formas de consumo. Desse modo, passa a acreditar na falsa ideia de que a ciência pode e deve conhecer tudo por representar a explicação causal da realidade tal como é em si mesma, visto que percebe a ciência não por seu processo de produção, mas por seus resultados e por seu poder social (CHAUÍ, 1997). No entanto, adquirindo importância social, o conhecimento científico poderia difundir-se na realidade vivencial e tornar-se significativo, pois a visão científica do mundo adentra profundamente o sistema de representações dos sujeitos e o transforma (STORT, 1993).

A ciência e a tecnologia devem ter representação social concreta, pois, enquanto sistema de conhecimentos e como conjunto constituído pelo saber/fazer, estas atividades embasam as vivências dos sujeitos. Nessa perspectiva, o sistema ciência/tecnologia atinge sua realidade vivencial e a apropriação do conhecimento científico promove um questionamento de seus saberes cotidianos, podendo possibilitar-lhes uma intervenção criativa e crítica na realidade na qual se inserem, tendo em vista sua compreensão e possível transformação. No contexto atual, a ciência continua detendo um conhecimento universalmente válido e suas formas de produção e seus efeitos sociais vêm se tornando cada vez mais visíveis. Considera-se que o desenvolvimento científico e tecnológico é um processo conformado por fatores culturais, políticos, econômicos, epistêmicos, valores e interesses que fazem da ciência e da tecnologia processos sociais. No entanto, a produção científica e tecnológica atual ainda não está acessível à maior parte dos cidadãos brasileiros, evidenciando também nesse âmbito uma desigualdade na distribuição das riquezas produzidas no país. Possivelmente, o aspecto mais sério da exclusão propiciada pelos avanços científicos e tecnológicos seja o efeito potencializador que estas atividades têm em criar novas formas de desigualdade, o que requer uma reconstrução urgente do ensino de ciências numa perspectiva crítica.

Apesar dos vínculos existentes entre o poder político-econômico, o desenvolvimento científico-tecnológico e a sociedade, na maior parte das vezes, o ensino de ciências ainda restringe-se ao oferecimento de conhecimentos prontos e acabados aos estudantes, sem considerar as ambiguidades decorrentes dos processos de produção e utilização dessas atividades. No âmbito da Educação Básica, o conhecimento científico continua sendo transmitido de modo consciente ou inconsciente, segundo as visões de mundo, de educação e de ciência que fundamentam o ensino desenvolvido pelos professores (NASCIMENTO, 2009). As mudanças promovidas pela atividade científico-tecnológica constituem um assunto público de extrema importância, portanto, é necessário construir as bases educativas para uma participação social consciente, assim como criar os mecanismos institucionais para fazer possível tal participação (GONZÁLEZ et al., 1996).

No contexto atual percebe-se uma maior vinculação entre os aspectos políticos e sociais e uma maior politização das atividades realizadas no âmbito da sociedade brasileira; assim, a ciência e o ensino de ciências deverão humanizar-se e assumir um caráter político e social, pois estas são atividades que podem possibilitar aos cidadãos novas formas de compreender a realidade, agir sobre ela e transformá-la (STORT, 1993; IRWIN, 1998).

Muitos dos problemas do ensino de ciências apresentam uma raiz epistemológica, haja vista a existência de relações, compatibilidades e incompatibilidades entre os ideais de cientificidade e a didática das ciências. A superação desse problema pressupõe mudanças teórico-metodológicas nos cursos de formação de professores de ciências, rupturas com uma concepção positivista de ciência - e de ensino de ciências - como acumulação de produtos da atividade científica e a construção de uma didática e uma epistemologia próprias, 
provenientes do saber docente.

\section{O oferecimento de uma formação crítico-reflexiva aos professores de ciências}

As questões conjunturais trazem graves consequências aos cursos de licenciatura em ciências, como a mudança de perfil dos estudantes que atualmente vêm optando por esses cursos, a separação existente entre as disciplinas de conteúdo específico e as disciplinas pedagógicas, a valorização dos cursos de bacharelado em detrimento dos cursos de licenciatura, a desarticulação entre formação acadêmica e a realidade escolar, dentre outros aspectos.

Os cursos noturnos de formação de professores de ciências são uma realidade no Brasil e apenas a partir dos anos 90 é que começaram a ser criados em maior número nas universidades públicas. A partir de 2002, com o plano de expansão das universidades federais, surgiram em número bastante significativo, tendo em vista reforçar e reorientar suas articulações com as escolas de educação básica e suprir a carência de profissionais nas redes públicas de ensino. No entanto, em alguns casos, esses cursos ainda funcionam com certa precariedade devido ao insuficiente envolvimento institucional das universidades e a problemas de natureza política, material e humana (PEREIRA, 2006).

Atualmente, algumas iniciativas têm procurado apontar caminhos para a superação dos problemas existentes nos cursos de formação de professores, tais como os fóruns permanentes de discussão e deliberação a respeito das problemáticas vivenciadas nas licenciaturas e as propostas de reformulação dos cursos em vigor em algumas universidades públicas brasileiras:

\footnotetext{
Os novos modelos apontam para o ensino baseado na construção do conhecimento pelo próprio aluno (futuro professor), que deve deixar a posição passiva de receber e compreender os ensinamentos passados pelo professor para assumir a posição de busca do próprio conhecimento, pela construção e significação de saberes a partir do confronto com situações reais ou simuladas da prática profissional, estimulando as capacidades crítico-reflexivas e de aprender a aprender (UNIVERSIDADE FEDERAL DE SÃO CARLOS, 2005, p. 25).
}

No entanto, mesmo quando as carências são apontadas e as propostas inovadoras surgem no âmbito das próprias universidades, tem sido difícil a promoção de mudanças. As tentativas de superação dos problemas das licenciaturas por meio de mudanças curriculares não têm ultrapassado os limites formais (LÜDKE, 1994).

No cotidiano da sala de aula o professor defronta-se com múltiplas situações divergentes, com as quais não aprende a lidar durante seu curso de formação, o que requer novas formas de agir e a construção de conhecimentos específicos da docência de forma reflexiva, crítica e processual, incorporando e transcendendo os conhecimentos advindos da racionalidade técnica (MIZUKAMI et al., 2002). O ensino reflexivo implica que os professores, ao invés de refletirem apenas sobre a aplicação em suas salas de aula das teorias geradas fora delas, critiquem e desenvolvam suas teorias práticas à medida que refletirem acerca de seu ensino e das condições sociais que modelam suas práticas educativas (ZEICHNER, 1993).

Nessa perspectiva, as propostas de formação de professores de ciências deverão considerar o papel da educação científica em diferentes contextos e a cultura científica dos professores no quadro da compreensão pública da ciência. Tal perspectiva considera que o 
conhecimento científico no espaço público deve ser sempre entendido como social e culturalmente adaptado segundo a perspectiva dos diferentes atores sociais. Os cursos de formação devem apresentar, portanto, responsabilidade social na busca de reconstrução da solidariedade, da liberdade e da dignidade humana, num estilo inquietante de construção do conhecimento emancipatório (VEIGA, 2002). A formação de professores de ciências deve ser entendida como uma oportunidade para reconstruir uma imagem de ciência menos fragmentada pelas fronteiras disciplinares (TORRES, 1994) e como um desafio na construção de um conhecimento emancipatório, essencial para a construção de uma sociedade verdadeiramente justa e democrática.

Considerando a importância de uma sólida formação científica, da participação democrática e da possibilidade de contribuição com a melhoria da qualidade de vida dos sujeitos, muitos são os desafios que se apresentam para a formação de professores de ciências. Não basta as universidades conceberem currículos que suportem uma cultura científica, pois é preciso promover mecanismos de formação de professores nesse sentido. Segundo o pressuposto de compreensão pública da ciência, é necessário considerar a heterogeneidade dos cursos de formação de professores de ciências e dos professores em formação, pois não está em causa somente a compreensão pública da ciência, mas também a compreensão científica dos públicos (IRWIN, 1998).

Formar professores de ciências pressupõe conceber e praticar uma formação científica que possibilite aos mesmos a apropriação de conhecimentos científicos relevantes do ponto de vista científico, social e cultural assim como a aprendizagem, o aperfeiçoamento e a construção de estratégias de ensino-aprendizagem, as possibilidades de reconstrução da tarefa de ensinar e motivação à curiosidade, à problematização, ao posicionamento crítico e à participação democrática responsável. É necessário possibilitar aos professores de ciências o desenvolvimento de atitudes reflexivas, da imaginação criadora, do desejo de investigar e agir sobre seus contextos de atuação e da compreensão do caráter aleatório e caótico colocados pela relação ciência-tecnologia-sociedade. Trata-se, portanto, de considerar a formação desse profissional sob uma perspectiva transformadora, segundo abordagens em que a incerteza não seja banida, mas gerida; em que os valores não sejam pressupostos, mas sim explicitados; em que a dimensão histórica, incluindo a reflexão sobre o passado, o presente e o futuro, torne-se parte integrante da caracterização científica da natureza; em que o local e o processual sejam relevantes para a explicação do mundo e para sua transformação.

No processo de formação de professores de ciências deve prevalecer um conhecimento-emancipação, possibilitando-lhes refletir sobre suas próprias práticas educativas, analisar e interpretar sua atividade profissional, fazendo da reflexão um instrumento de desenvolvimento do pensamento e da ação crítica. Refletindo criticamente sobre seu papel e sobre as possibilidades educativas do ensino de ciências, os professores poderão desenvolver uma maior competência pedagógica e auxiliar os estudantes na construção de saberes estratégicos e emancipatórios. Nesse processo, os conhecimentos que os professores devem construir vão além de regras, fatos, procedimentos e teorias estabelecidas pela investigação científica (PÉREZ GÓMEZ, 1992). A reflexão sobre as próprias práticas educativas pode favorecer-lhes a construção de teorias adequadas às singulares situações nas quais se encontram e possibilitar-lhes o desenvolvimento de estratégias de ação num processo no qual se reeducam criticamente e aperfeiçoam constantemente suas práticas educativas.

Os professores de ciências devem ser elevados à qualidade básica de cidadãos; nos cursos de formação devem ter possibilidades de vivenciar atividades formativas que lhes possibilitem o desenvolvimento de formas mais elaboradas de pensamento, a compreensão 
do significado educativo, político e social do ensino que desenvolvem, vislumbrar uma atuação consciente, ética e responsável:

O professor, durante sua formação inicial ou continuada, precisa compreender o próprio processo de construção e produção do conhecimento escolar, entender as diferenças e semelhanças dos processos de produção do saber científico e do saber escolar, conhecer as características da cultura escolar, saber a historia da ciência e a história do ensino da ciência com que trabalha e em que pontos elas se relacionam. Esses elementos constituem apenas uma das características do trabalho docente e, sem desconhecer as outras dimensões, já revelam e demonstram a sua complexidade. (PEREIRA, 2006, p. 47)

A formação crítico-reflexiva de professores de ciências deve também considerar a construção coletiva de propostas educativas no âmbito das escolas, pois a construção de conhecimentos específicos da docência não surge a partir da aplicação de procedimentos técnicos elaborados e impostos por agentes educacionais externos, mas requer um processo sistemático e contínuo de formação profissional, privilegiando as escolas como espaços formativos para que esses profissionais possam alcançar a estrutura profissional desejada (MEDINA E DOMÍNGUEZ, 1989; NÓVOA, 1992). O exercício crítico-reflexivo da docência requer que tenham uma sólida formação que os leve a refletir constantemente sobre os significados político, social e educativo do ensino que desenvolvem. Considerando as articulações entre a educação e o contexto sócio-político-econômico, é imprescindível que assumam um compromisso claro com a educação e com a sociedade e se tornem agentes de mudanças (GIROUX, 1987; VASCONCELOS, 1998; NASCIMENTO, 2009).

Melhorar a formação de professores de ciências pressupõe reforçar o papel da socialização e da valorização humana e requer que sejam considerados como pessoas cidadãs, sobre as quais recaem responsabilidades profissionais e sociais.

\section{CONSIDERAÇÕES FINAIS}

A história do ensino de ciências no Brasil deixa evidente que tanto o ideário educacional quanto as ideias a respeito da produção científica e tecnológica influenciaram e continuam influenciando esse ensino.

No âmbito do capitalismo industrial, as ciências passaram a preocupar-se não apenas com a compreensão da natureza, mas principalmente com sua exploração e dominação, o que possibilitou mudanças no ensino de ciências. Nesse contexto, surgiu a escola tecnicista na qual a apropriação do saber identificava-se com o poder e os sujeitos deveriam ser conduzidos como máquinas para que produzissem mais e melhor, tendo em vista garantir uma maior lucratividade para os donos das organizações (VIANNA, 2004).

Até o final dos anos 1970, a busca por melhorias no ensino de ciências esteve mais vinculada aos processos de produção e divulgação do conhecimento científico, do que aos avanços das pesquisas sobre a didática das ciências. Atualmente, o ensino de ciências ainda reflete muitas ideias inerentes ao desenvolvimento científico das décadas de 1950, 1960 e 1970, certa esperança depositada na ciência para a solução dos problemas da humanidade e, paradoxalmente, problemas sociais e ambientais provocados pela atividade científica e tecnológica (KRASILCHIK, 1998). Em meados dos anos 1970 tais pressupostos já eram criticados, o que gerou um movimento por mudanças no ensino de ciências, embora nas escolas este ensino pouco tenha sido modificado. 
Nas décadas de 1980 e 1990, parte significativa das propostas de melhoria do ensino de ciências trazia subjacente graves deficiências epistemológicas e didáticas, dificultando a formação do sujeito crítico, consciente e participativo.

Historicamente, o oferecimento de uma sólida formação científica e pedagógica aos professores sempre foi considerada uma condição essencial para a melhoria do ensino de ciências. No entanto, a formação desses profissionais acompanhou as diretrizes de propostas educativas estrangeiras, concretizou as singularidades político-econômicas vigentes de cada época e reproduziu, em muitos casos, os interesses da classe dominante.

A construção de um ensino de ciências de qualidade pressupõe urgentemente romper com o modelo de formação docente que prevalece na maior parte das universidades brasileiras, no qual são ensinados os produtos da ciência e oferecidas possibilidades didáticas para o ensino dos mesmos nas escolas. A universidade não pode continuar formando professores de educação básica como uma espécie de tarifa que paga para poder fazer ciência. É imprescindível que assuma essa formação como uma de suas tarefas centrais (MENEZES, 1987).

Na formação do professor de ciências defende-se a articulação entre teoria e prática pedagógica, pesquisa e ensino, reflexão e ação didática. No entanto, a separação explícita entre ensino e pesquisa nas universidades e a valorização da pesquisa em detrimento das atividades de ensino ainda trazem enormes prejuízos a essa formação (PEREIRA, 2006).

A formação do professor inicia-se antes mesmo de seu ingresso no curso de licenciatura, prosseguindo ao longo de toda sua carreira profissional. O futuro professor de ciências chega ao curso de formação carregando imagens a respeito da ciência, do ensino de ciências, da função da escola e da atividade docente. Sua formação deve estar fundamentada na reflexão crítica sobre as práticas educativas e na (re)construção permanente de sua identidade, daí a importância do investimento na pessoa do professor e nos saberes advindos de sua experiência (NÓVOA, 1992). As mudanças nos processos de formação de professores de ciências deverão ocorrer tanto no âmbito pessoal quanto no âmbito institucional (NÓVOA, 1992; MIRTHA, LAVIN e MURÚA, 1996).

Apesar de, historicamente, as propostas de mudanças na educação escolar não terem sido acompanhadas de melhorias nas condições subjetivas e objetivas de trabalho dos docentes, melhorias significativas no ensino de ciências pressupõem não apenas mudanças na formação dos professores, mas também nos contextos nos quais desenvolvem suas práticas educativas.

No atual contexto sócio-político-econômico brasileiro estão surgindo muitas modificações no espaço-tempo social, que representam uma diversificação das formas de pensar a construção da cidadania e pressupõem a possibilidade de construção de uma sociedade onde não existam sujeitos privilegiados, ou seja, de uma utopia ecológica e democrática cujos protagonistas poderão ser todos aqueles que constituem as práticas sociais (SOUSA SANTOS, 1994). Nesse contexto, aprender a ser professor não significa meramente apropriar-se de conteúdos e técnicas de ensino. Trata-se de uma aprendizagem que deve ocorrer por meio de situações práticas efetivamente problemáticas, o que exige a construção de uma prática educativa reflexiva e crítica.

Ensinar ciências no cenário atual requer que os professores compreendam as origens das inovações científicas e tecnológicas; lutem contra as desigualdades impostas pelo capital e pelo exercício do poder; e abram novos horizontes aos estudantes no sentido de se desenvolverem humana e integralmente. A eficácia do trabalho do professor de ciências está diretamente relacionada à capacidade de articular práticas educativas às práticas sociais, ou seja, o trabalho desenvolvido nas escolas com o processo de democratização e reconstrução da sociedade (SAVIANI, 1997). 
A construção de uma sociedade verdadeiramente democrática, justa e equitativa pressupõe, também, uma formação científica que permita ao cidadão perceber e agir no sentido de substituição da ética neoliberal por uma ética não individualista e não colonizada pela ciência e pela tecnologia, o que requer na escola a vivência da reflexão e a construção de conhecimentos científicos numa perspectiva emancipatória (VEIGA, 2002; NASCIMENTO, 2009).

\section{REFERÊNCIAS}

AIKENHEAD, G. S. The social contract of science: implications for teaching science. New York: Teachers College Press, 1994.

ALONSO, A. Et alii. Para comprender ciencia, tecnología y sociedad. Estella: EVD, 1996.

ARROYO, M. G. Quem de-forma o profissional do ensino? Revista de Educação AEC, Brasília, 14(58): 16-21, outubro/dezembro, 1985.

BASSO, I. S. As condições subjetivas e objetivas do trabalho docente: um estudo a partir do ensino de história. Campinas: FE-UNICAMP, 1994 (tese de doutorado).

BRASIL. Ministério da Educação. Proposta de diretrizes para a formação inicial de professores da educação básica em cursos de nível superior. Brasília, DF: MEC, 2001.

CANAVARRO, J. Ciência e sociedade. Coimbra: Quarteto, 1999.

CANDAU, V. M. F. Formação continuada de professores: tendências atuais. In: REALI, A. M. M. R. e MIZUKAMI, M. G. N. (orgs.). Formação de professores: tendências atuais. São Carlos: Ed. UFSCar, 1996, p. 139-152.

CARVALHO, A. M. P. e GIL-PÉREZ, D. Construção do conhecimento e ensino de ciências. Em Aberto. Brasília, 55, 61-67, 1992.

CHASSOT, A. Ensino de ciências no começo da segunda metade do século da tecnologia. In: LOPES, A. C. e MACEDO, E. (orgs.). Currículo de ciências em debate. Campinas: Papirus, 2004, p. 13-44.

CHAUÍ, M. Convite à filosofia. São Paulo: Ática, 1997.

DELIZOICOV, D. e ANGOTTI, J. A. Metodologia do ensino de ciências. São Paulo: Cortez, 1990.

DEMO, P. Professor e seu direito de estudar. In: SHIGUNOV NETO, A. e MACIEL, L. S. B. (orgs.). Reflexões sobre a formação de professores. Campinas: Papirus, 2002, p. 71-88.

DYSON, F. Can science be ethical? The New York Review of Books XLIV/6, 46-49, 1997.

ECHEVERRÍA, J. Filosofía de la ciencia. Madrid: Akal, 1995.

FOUREZ, G. Alfabetización científica y tecnológica. Acerca de las finalidades de la enseñanza de las ciencias. Buenos Aires, Colihue, 1997.

FROTA PESSOA, O. et alii. Como ensinar ciências. São Paulo: Nacional, 1987.

GENTILI, P. A. A. e SILVA, T. T. (orgs.). Neoliberalismo, qualidade total e educação: visões críticas. 8. ed. Petrópolis: Vozes, 1999. 
GIL PÉREZ, D. ¿Qué han de saber y saber hacer los profesores de ciencias? Enseñanza de las Ciencias, 9 (1), 69-77, 1991.

El papel de la educación ante las transformaciones científico-tecnológicas. Revista Iberoamericana de Educación. 18, 11-23, 1999.

GIMENO SACRISTÁN, J. El profesor como investigador en el aula: un paradigma de formación de profesores. Educación y Sociedad, 2, 51-73, 1983.

GIROUX, H. Teoria crítica e resistência em educação: para além das teorias de reprodução. Petrópolis: Vozes, 1987.

GONÇALVES, M. E. Cultura científica e participação pública. Oieiras: Celta Ed, 2000.

GONZÁLEZ, G. M. et alii. Ciencia, tecnología y sociedad: una introducción al estudio social de la ciencia y la tecnología. Madrid: Tecnos, 1996.

HENNIG, G. J. Metodologia do ensino de ciências. Porto Alegre: Mercado Aberto, 1994.

HODSON, D. Philosophy of science and science education. Journal of Philosophy of Education, 12, 25-57, 1986.

e REID, D. J. Science for all: motives, meaning and implications. School Science Review, 88, 653-667, 1998.

IRANZO, J. M. et alii. Sociología de la ciencia y la tecnología. Madrid: CSIC, 1995.

IRWIN, A. Ciência cidadã. Lisboa: Instituto Piaget, 1998.

JIMÉNEZ, M. P. e OTERO, L. La ciencia como construcción social. Cuadernos de Pedagogía. 180, 20-22, 1990.

JOULliÉ, V. \& MAFRA, W. Didática de ciências através de módulos instrucionais. Petrópolis: Vozes, 1980.

KRASILCHIK, M. O professor e o currículo das ciências. São Paulo: EPU/EDUSP, 1987.

- Formação de professores e ensino de ciências: tendências nos anos 90. In: MENEZES, L. C. (Org.). Formação continuada de professores no contexto iberoamericano. São Paulo: NUPES, 1996, p.135-140.

. Prática de ensino de biologia. São Paulo: Harbra, 1998.

LÓPEZ CEREZO, J. A. Ciencia, tecnología y sociedad. Una introducción al estudio social de la ciencia y la tecnología. Madrid: Tecnos, 1999.

LÜDKE, M. Avaliação institucional: formação de docentes para o ensino fundamental e médio (as licenciaturas). Cadernos CRUB, v.1, n.4, Brasília, 1994.

MACEDO, E. Ciência, tecnologia e desenvolvimento: uma visão cultural do currículo de ciências. In: LOPES, A. C. e MACEDO, E. (orgs.). Currículo de ciências em debate. Campinas: Papirus, 2004, p. 119-153.

MARCELO GARCÍA, C. Constantes y actuales desafíos de la profesión docente. Revista de Educación. 306, 205-243, 1995.

MARCO, B. La alfabetización científica en la frontera del 2000. Kikirikí, 44-45, 35-42, 1997. 
MARTINS, M. A. V. Reflexões acerca do formar professores. In: RIVERO, C. M. L. e GALLO, S. (orgs.). A formação de professores na sociedade do conhecimento. Bauru: Edusc, 2004, p. 55-77.

MEDINA, A. e DOMÍNGUEZ GARRIDO, M. C. La formación del profesorado en una sociedad tecnológica. Madrid: CINCEL, 1989.

MEDINA, M. e SANMARTÍN, J. Ciencia, tecnología y sociedad: estudios interdisciplinares en la universidad, en la educación y en la gestión pública. Barcelona: Anthropos, 1992.

MEMBIELA, P. CTS en la enseñanza-aprendizaje de las ciencias experimentales. Alambique. 3, 7-12, 1995.

MENEZES, L. C. Formar professores: tarefa da universidade. In: CATANI, B. et alii. (Orgs.). Universidade, escola e formação de professores. São Paulo: Brasiliense, 1987, p. 115-125.

Características convergentes no ensino de ciências nos países ibero - americanos e na formação de seus professores. In: MENEZES, L. C. (Org.). Formação continuada de professores no contexto ibero-americano. São Paulo: NUPES, 1996, p. 45-58.

MIRTHA, A., LAVIN, S. e MURUA, V. La formación de profesores de enseñanza básica en la perspectiva del año 2000. Santiago de Chile: PIIE/FONDECYT, 1996.

MIZUKAMI, M. G. N. Docência, trajetórias pessoais e desenvolvimento profissional. In: REALI, A. M. M. R. e MIZUKAMI, M. G. N. (Orgs). Formação de professores: tendências atuais. São Carlos: UFSCar, 1996, p. 59-91.

. et alii. Escola e aprendizagem da docência: processos de investigação e formação. São Carlos: EdUFSCar, 2002.

NASCIMENTO, F. Pressupostos para a formação crítico-reflexiva de professores de ciências na sociedade do conhecimento. In: MIZUKAMI, M. G.. N. e REALI, A. M. M. R. (orgs.). Teorização de práticas pedagógicas: escola, universidade, pesquisa. São Carlos: UdUFSCar, 2009, p. 35-72.

NÓVOA, A. Formação de professores e profissão docente. In: NÓVOA, A. (Org.). Os professores e sua formação. Lisboa: Dom Quixote, 1992.

PEREIRA, J. E. D. Formação de professores: pesquisas, representações e poder. $2^{\mathrm{a}}$ ed. Belo Horizonte: Autêntica, 2006.

PÉREZ GÓMEZ, A. I. La función y formación del profesor en la enseñanza para la comprensión: diferentes perspectivas. In: PÉREZ GÓMEZ, A. I. e GIMENO, J. Comprender y transformar la enseñanza. Madrid: Morata, 1992, p. 398-429.

SAVIANI, D. Pedagogia histórico-crítica: primeiras aproximações. São Paulo: Autores Associados, 1997.

SCHÖN, D. A. Formar professores como profissionais reflexivos. In: NÓVOA, A. (Org.). Os professores e sua formação. Lisboa: Dom Quixote, 1992.

SOUSA SANTOS, B. Pela mão de Alice: o social e o público na pós-modemidade. Porto: Ed. Afrontamento, 1994. 
STORT, E.V.R. Cultura, imaginação e conhecimento: a educação e a formalização da experiência. Campinas: Ed. UNICAMP, 1993.

TORRES, R. M. Que (e como) é necessário aprender? Campinas: Papirus, 1994.

Tendências da formação docente nos anos 90. In: Novas políticas educacionais: críticas e perspectivas. II Seminário Internacional. PUC-SP, 1998, p. 173-191.

UNIVERSIDADE FEDERAL DE SÃO CARLOS. Projeto pedagógico do curso de licenciatura em ciências biológicas. São Carlos: UFSCar, 2005 (relatório).

VACCAREZZA, L. S. Ciencia, tecnología y sociedad: el estado de la cuestión en América Latina. Revista Iberoamericana de Educación. 18, 21-33, 1999.

VARSAVSKY, O. Ciencia, política y cientificismo. Buenos Aires: CEAL, 1979.

VASCONCELOS, C. S. Para onde vai o professor? Resgate do professor como sujeito de transformação. São Paulo: Libertad, 1998.

VIANNA, I. O. A. A formação de docentes no Brasil: história, desafios atuais e futuros. In: RIVERO, C. M. L. e GALLO, S. (orgs.). A formação de professores na sociedade do conhecimento. Bauru: Edusc, 2004, p. 21-54.

VEIGA, M. L. Formar para um conhecimento emancipatório pela via da educação em ciências. Revista Portuguesa de Formação de Professores. 2, 49-62, 2002.

WYNNE, B. Public understanding of science. In: JASANOFF, G. M. e PETERSEN, T. P. (eds.). Handbook of Science and Technology Studies. Thousand Oake: Sage, p. 361-387, 1995.

YUS, R. Los enfoques CTS: una forma de globalizar en el área de ciencias de la naturaleza. Kikirikí, 44-45, 11-22, 1997.

ZEICHNER, K. M. El maestro como profesional reflexivo. Cuadernos de Pedagogía, 220, 44-49, 1993.

\footnotetext{
${ }^{1}$ Professor Adjunto da Universidade Federal de São Carlos - campus de Sorocaba. Email: fnascimento@ufscar.br

2 Professor Adjunto da Universidade Federal de São Carlos - campus de Sorocaba. Email: hylio@ufscar.br

${ }^{3}$ Professora Adjunta da Universidade Federal de São Carlos - campus de Sorocaba. Email: viviane@ufscar.br
}

Artigo recebido em: 16/09/10

Aprovado em: 30/10/10 